Faculty retention: Strategies suggested by faculty members of select private universities in Dhaka city

\author{
Abdullah, Abu Md. \\ Faculty of Business Administration, Eastern University, Bangladesh (abdullah@easternuni.edu.bd) \\ ISSN: $2243-7770$ \\ Online ISSN: 2243-7789 \\ OPEN ACCESS
}

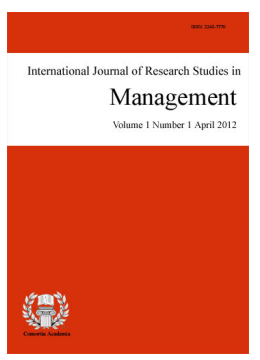

\title{
Abstract
}

Employee retention is of paramount importance today. Organizations face a tough time in developing their human resources as they treat employees only as means of production and that is why employee retention strategies are essential to practice because employees are more than just a mean of production. When an employee does not get the proper treatment, evaluation and satisfaction from job, they decide to leave which make huge losses when the employees have been working for a long time. This study outlines the suggestions provided by employees. The purpose is identifying the retention strategies they want to see implemented. One hundred faculty members were chosen as the respondent group from five private universities in Dhaka city at Dhanmondi area. They were asked to provide one employee retention strategy that they want to see implemented by their respective organizations. The suggested strategies have been described. Aligning skills with jobs, a mind reader boss, valuing experience were some highly mentioned suggestions respondents opted for.

Keywords: retention; employee; human resource; strategy; organization 


\section{Faculty retention: Strategies suggested by faculty members of select private universities in Dhaka city}

\section{Introduction}

Employee retention is an endeavor by a business to sustain a working environment which supports existing staff in remaining with the company. Several employee retention policies are aimed at targeting the various needs of employees to increase their job satisfaction and reduce the significant costs associated with hiring and training new staff. It is a procedure in which the employees are made motivated to stay with the organization for the maximum period of time (Nazia \& Begum, 2013). Today's business environment, the role-playing of human resource is strategic instead of supporting administrative tasks, as with time, it has been proved that the greatest assets of the organization are its people. It is a prime duty of an organization to effectively manage the talent of its workforce to achieve business objectives (Peggy \& Bernard, 2016).

If employees feel disappointed with the current employer or the job, they decide to shift to another job in a different organization. So, it is the responsibility of the employer to retain their best employees. If they fail to retain then they would be left with no talented employees at all. A good employer should know how to not only attract but also retain its employees in the long run. Employee Retention engages applying measures to encourage employees to remain in the organization for the maximum period of time. Organizations today are facing a lot of hurdles in employee retention these days. Hiring competent people for the job is essential for an employer. But retention is clearly more important than hiring because there is no shortage of opportunities for a talented person (Abdali, 2011). Employee turnover has definitely a cost to pay for the organizations. Too much employee turnover often creates in-depth penalty and, at the extreme, may endanger efforts to attain organizational objectives. When an organization loses a critical employee, there is a downbeat impact on innovation; stability in providing service to customers may be jeopardized (Abbasi \& Hollman, 2000).

Fitz-enz (1997) proved that the average company loses approximately $\$ 1$ million with every 10 managerial and professional employees who depart the organization. There is a noteworthy monetary impact when an organization loses any of its critical employees, especially given the

Knowledge that is lost with the employee's exit. It will become considerably more important in the coming years to recognize the dedication of individuals to an organization, as well as the organization's need to create an environment in which one would be willing to stay (Harris, 2000). Organizations put time and money to mold a new employee to turn into a corporate-ready material like existing and veteran employees. The organization is entirely at a loss when the employees go away from their job once they are fully competent after being trained. Employees, who depart an organization, leave with knowledge regarding the organization, its customers, past history and even the organization's current projects and business strategy (Choudhary, 2016). That is why it is crucial to know about the employees' feelings, their opinions and suggestions to understand them better to utilize their talent retaining them.

\subsection{Educational sphere and retention specialties}

Teaching sector has certain unique elements. Conducting classes and examinations, dealing with students, advising, coordinating extracurricular activities, writing a research paper, arranging seminars, workshops on teaching and learning are some major activities in teaching environment at the university level. So decision to stay or leave and job satisfaction derives from comfort in performing those activities. Employee retention depends on how faculty members are being treated. As it is not a typical corporate job, what motivates and retains employees in a factory or corporate office environment is not all the same in case of teaching. Some factors that influence retention negatively in the educational sector, especially at the university level are: more of 
Faculty retention: Strategies suggested by faculty members of select private universities in Dhaka city

clerical tasks instead of creative work, lack of academic leadership, unavailability of sabbaticals, lack of research facilities etc. (Jadhav, Jadhav, \& Lavanya, 2014).

Retaining good teachers is nothing less than a challenge. Firstly, not many form this desire to be a teacher in comparison with the number of people who want to join the corporate sector. When easy money grows at the hand of people in an early stage, passion for study and education sector starts to decline. But not a second person will disagree that the success, vision, prosperity depend on the hands of the teacher who can inspire and motivate students to be independent and social being in life in coming days. To many of students in graduation level, it's their teachers who have secured the place of the ideal person or role model. So the significance of retaining teachers cannot be overemphasized.

Before trying to retain faculty members it is imperative to know about the reasons for which they quit or switch their jobs or what makes them leave. When faculties do not find any cooperative setting in the workplace for a long time, any attachments to the workplace fails to grow. If they have to be busy with administrative jobs more than the academic job, if necessary support from the officials and staff is hard to reach, if monthly salary is delayed for instances people lose their job interest. There comes a time after some years spent in teaching where faculties don't see any value addition in their personal as well as professional life. They feel stuck at their careers. When the quality of students' drops, universities fail to offer interesting projects to faculties to tap into their latent qualities, they form a desire to quit teaching.

So retaining faculty is crucial for a successful teaching sector. Some other causes are there as well, for example, recruiting teachers takes investment and lots of brainwork with a planning to sustain with them in future, now if teachers leave after a few days, then universities face huge loss in terms of lost training and development cost coupled with recruitment cost as well. When teachers leave this way in the middle of a semester, other teachers are to be managed all of a sudden to continue the leftover courses. Certainly, it creates lots of discomfort and dissatisfaction among students and teachers. Good teachers are also irreplaceable. Loss of such faculty is felt for a long time. Sometimes, universities do not care about the people quitting jobs, they become busy hiring new ones rather than focusing on the reason for quitting jobs. If this continues, universities loose reputation. Retention of faculties is also significant because an accomplished teacher works like a social icon and catalyst for change, students look up to and consider as a role model. Importance of such teachers on the personal and social life of students is extraordinary. So loosing such talented faculties creates a vacuum and it remains like that.

\subsection{Objective of the study}

This study is carried out mainly to accumulate the suggestions or opinions of employees regarding the desired retention practice in order to develop the human resource for the long term. The study will be helpful to human resource managers and administrators of private universities to reduce the rates of teachers' turnover and consequently ensure a stable and well-motivated staff in private universities.

\section{Literature review}

Oginni, Ogunlusi, and Faseyiku (2013) told that the tactic used by employers to get employee's contentment and dedication to organizational goals and aspirations is retention strategy where it is the extent of practice that would decide the impact of retention strategy on employees. Arik (2011) went ahead to break up retention factors into two categories: pull and push factors where the factors within the organization that make employees depart are termed push while those factors outside the organization in the external environment are called the pull factors. Gary (2008) said retention means a methodical attempt by an employer to generate and promote an environment that encourages current employees to stay employed by having policies and practices in place that deal with their multifarious needs. It can then be inferred that employee retention strategies are policies and practices organization takes up to prevent valuable employees from leaving their job while at the same time 
securing their faith and loyalty so as to have less of desire to leave in the future. Cynthia (2007) was of the belief that for significant retention strategies, efforts should be made to be aware of the various reasons why employees leave their organization. His identified reasons included - no growth opportunities, job and person mismatch, lack of appreciation, lack of trust and support for co-workers, stress from overwork, work-life imbalance, poor compensation package among others.

Allan (2004) pointed out the accumulated benefits of retention strategies namely reduction in the cost of labor turnover, increasing company knowledge, uninterrupted service leading to organizational goodwill, enhanced efficiency of business and operation. Lincoln (1996) proposed the following basic practices which should be reviewed before developing strategies for retention; hire the right categories of people, make employees realize that they are the most valuable asset of the organization, trust, and respect, provide feedback, keep their morale high and vary bonus from position to position.

Fitz-enz (1990) documented that employee retention is not influenced by a single factor, but there are groups of factors which are responsible for retaining employees in an organization. Management is required to pay attention to factors such as compensation and rewards, job security, training and developments, supervisor support culture, work environment and organization justice etc. According to Osteraker (1999), the employee satisfaction and retention play pivotal roles in the success of an organization. The Retention factor can be classified into three large dimensions - social, mental and physical. The mental dimension of retention contains work characteristics, employees always prefer flexible work tasks where they can use their knowledge and see the results of their efforts which, in turn, helps in retaining the valuable resources.

The social dimension composed of the contacts that the employees have with other people, both internal and external. The physical dimension is about working conditions and pay. Stein (2000), Clarke (2001), Parker and Wright (2001) have precisely observed that organizations have got to utilize a wide range of human resource management factors to influence employee commitment and retention. Walker (2001) proposed seven factors that can improve employee retention: (i) compensation and appreciation of the performed work, (ii) scope of challenging work, (iii) chances to be promoted and to learn, (iv) invitational atmosphere within the organization, (v) positive relations with colleagues, (vi) a healthy balance between the professional and personal life, and (viii) effective communications. Hytter (2007) showed that factors such as personal premises of loyalty, trust, commitment, and identification and attachment with the organization have a direct impact on employee retention. Kyndt, Dochy, Michielsen, and Moeyaert (2009) found in their study, while exploring employee retention that personal factors such as level of education, seniority, self-perceived leadership skills, and learning attitude and organizational factors such as appreciation and stimulation, and pressure of work are of great relevance in employee retention.

Eyster, Johnson, and Toder (2008) notified that job flexibility with lucrative career and life options is a vital inducement for all employees. Hewitt (2002) mentioned that modern businesses always keeps its employees well informed about all the significant affairs of its business and involves them in decision-making at all levels which can develop the talents of its employees. Supporting the view Noah (2008) described in his research that employee attachment in decision-making helps in creating a sense of belongingness among the employees, which helps in creating a good amiable working environment and contributes towards building a good employer-employee relationship. According to Miller, Erickson, and Yust (2001), employees are often benefited by the work environment that offers a sense of belongingness. Wells and Thelen (2002) have stated in their study that organizations which have kind human resource policies have a very good probability to satisfy and retain employees by providing them a suitable level of privacy and sound control on work environment which develops the motivation levels to commit with the organization for the long term. Garg and Rastogi (2006) enlightened that in today's competitive environment feedback is very indispensable for organizations from employees.

Numerous articles have been written on the retention strategies but there was lack of sufficient record of effort exerted to elicit responses from employees regarding suggestions to retain them by the help of an in-depth 
Faculty retention: Strategies suggested by faculty members of select private universities in Dhaka city

personal query. This article highlights some ways or strategies that faculty members want to see in practice.

\section{Methodology of the study}

To conduct this study a questionnaire was designed that mainly was directed to know their suggestions to make the employee retention practice effective to develop the long-term human resource. Two weeks of time was required to complete this survey. A survey was carried out among 100 teachers of 5 University Grants Commission (UGC) approved private universities in the Dhanmondi area. So it was a cluster sampling. Faculty members with minimum 7 years of working experience were selected. This was on purpose because the objective was to collect suggestion from teachers who have worked a long time and experienced more than young ones. The reason behind choosing this group of the respondent is that it is assumed that teachers with long working experience in the same organization have more knowledge about the retention practice of the organizations as they have worked more and observed more than the younger ones. So they are the source of information. 20 teachers from each university were selected who has stayed over at least 7 years. The research question was simple. Each respondent was asked to point out and explain one single employee retention strategy that they would like to see practiced by their organization to maintain a desired employee retention techniques to develop a productive set of human resource for the long term. There was no missing data. All 100 employees have answered properly. From the answer sheets, the responses or suggestions have been counted and presented here based on higher frequency. Twelve suggestions or retention strategies were found. Those suggestions have been discussed in the findings section with the relevant quotation in descending order.

\section{Findings and analysis}

> Aligning background with job duties: Majority of employees suggested that they would be more productive and work life could not be monotonous if jobs could be designed based on the background - their competencies, achievements in early life. One striking finding was written like "our resumes speak about our skill profiles, qualifications and competencies but unfortunately after the recruitment, that thing gets a backseat. It would be a fresh change in the workplace if we would find that our resumes are reevaluated and works are being assigned based on our strengths and desires." It reveals the fact that after joining an organization, employees keep performing tasks some of which don't match with their skill profiles eventually it creates a kind of frustration. So employees want, for a change, a task offered to match their skills by studying their background will make a notable change in performing better.

$>\quad$ Valuing experience: One group of employees suggested that it will keep them with full cooperation if their experiences are being valued. One notable response was - "There comes a time when people differ in terms of experience even in the same rank of a job. I feel highly inspired to work and dedicated to my organization when I find my experience is being given importance in the decision-making process. Sometimes I want to be in privacy to be away from chaos. If such arrangements can be provided, I will be highly motivated to stay long" These employees feel that they can be retained well if their experience is considered.

$>$ Continuous follow-up: Some other respondents pointed out that top management should look after the recruited employees on a regular form whether it is in a formal or informal way because it shows employees are being taken care of. They make it clear by saying - "employees should not be faded, new employees will join. Keep joining but older ones should not be forgotten." All they need is a sense of being valued and respected in the same way they were treated in the beginning.

$>$ A mind reader boss: Another group of employees opined that people change with time. Priority in life, goals also keep changing. Sometimes people stop being sociable, still, the job runs and at that time people expect a pep talk with a departmental head to share and to be understood. One highlighting 
response was - "I wish one fine day my boss would call me and appreciate my effort that I think going unnoticed, would ask how I am doing and feeling after working so many years, this one single gesture would increase my motivation to work." This very thought signifies the fact that employees at a certain point, want to be understood by being called and noticed by the head to increase the feeling of being retained.

D Giving equal value to all: Some employees suggested that if employees are treated fairly; they will keep working with zeal. They mainly opined that - when it comes to evaluating performance, one single criterion to judge should be fairly exercised. The scrutinizing process should be the same for all employees at the same level. One respondent assured that - "All my life I practiced and opted for the same - being fair in my judgment. Not to be biased by any personal influences. It hurts me to see some alteration of rules to excuse some preferred ones over other ones. "This feeling of being treated equally or fairly enhances the attachment giving a positive indication to employees about a well thought out retention strategy.

$>$ Breaking stereotypes: One group of employees put their suggestion by pointing out this phenomenon. Their common response was - "Scope to perform ad-hoc duties should be assignable to all employees with consent that will prove the impartiality of organization." if sudden duties or set projects are imposed to the same person in every term and it becomes a norm for the organization it creates dissatisfaction and people become reluctant to work. After working in the same position for years, getting to work something different that will be a new trendsetter is what employees want.

> Understanding distinctive work pattern: Some other faculties pointed out that their boss or departmental head needs to know that people work from different perspectives and they have a different working pattern. They mainly suggested that "To retain employees, you need to know their worth, to know the worth, it is important to know the work pattern of employees which varies to a greater extent." Not all teachers work in the very same fashion, people joining a workstation have diverse background and life history and it is an ability to culminate and utilize their diversity for a better workplace. Feeling of being recognized for distinctive work pattern fuels the desire boosting loyalty for the organization.

$>$ Practicing job rotation: There are a lot of tasks to do and roles to play for a faculty in a private university. There are many projects works also for students, for promoting research as well. If a faculty member is tired of doing the teaching and shows interest over other works like arranging programs like a career fair, entrepreneurship fair to name a few, there should be a rotation, again after a few sessions, this scope should go to another visionary faculty. Such rotation system keeps refreshing faculty members and increase motivation for the job. The common view among the five respondents was "It is high time I get to change my job from teaching to some other things like arranging research workshop and maintaining corporate liaison, student counseling etc. for some days to take a break from regular teaching. "The plus side of this practice according to them is that it offers a break from the regular job and they get to engage in something different that is motivating and recharging.

$>$ Removing fear of job insecurity: Retaining employees will not be possible if there is fear of job insecurity. A continuous feeling of threat to lose the job can never bring good outcome from employees. Not all employees have the intention of switching the job to other organization. Some employees are content with their jobs considering some issues like less distance from home for commuting, congenial work environment, a good working relationship with colleagues and students. If the university does not consider these issues and fails to ensure job security for its loyal employees it creates a deep impact and a feeling of threat in the minds of employees. The common view is "It does not feel good that the organization that I prefer to work is not being able to reduce my fear rather 
Faculty retention: Strategies suggested by faculty members of select private universities in Dhaka city

in each faculty meeting the same issue of job insecurity is raised. It gives a feeling of fear that if for some unwanted reason or for some political reason, my job is terminated, how will I survive? It takes time to get absorbed in the job market. "The employees suggested that they would like to contribute more if there is no threat or no such discussion and practice of job sacking which has no clear explanation.

$>$ Eliminating undue influence: To retain employees a biased free work environment is a precondition for many teachers who value this virtue. Grouping is a common phenomenon in organizational culture. When this works each workgroup tries to manipulate others and in this process, some neutral employees face problems. The common view in this regard is - "When my credential is subject to the influence of other colleagues for annual performance review, it creates a tension as I know very well that my boss is likely to get influenced by the opinion of other colleagues who are close to him I just do not like this environment to work in." working in unbiased environment is a dream that enhances performances.

$>\quad$ Offering personal discretion on the job: Faculties do want a liberating work environment, where they will enjoy a certain amount of autonomy over their job. One respondent described it like - "I do not like this system where my job will be dictated and observed closely giving me no freedom to be creative in each phase from devising course outline to conducting classes and making question papers and copy checking. I wish I could work in an environment where I would be given some authority and freedom to devise my work process my way." This point mainly discusses the need for discretion to an extent to excel. This one strategy if practiced can retain its faculties.

> Increasing increment: The annual increment provided to faculties is really insignificant which hardly fills up the need. Employees want their annual increment to be significant enough to keep them happy to stay for longer time. Not all employees have second income source apart from the job, so to compensate for the increasing demand, a healthy amount of increment is essential to maintain the life standard as in the market where the price of a commodity increases rapidly. The major concern is like - "The increment should reflect the inflation in the economy. If the rate of increment is poor or static over the years, it does not add value; it becomes too difficult to cope up with increasing family needs with the insignificant increment."

Money matters for most of the job holders. Time value of money is also a matter of concern, so if the bonus or basic pay or other allowances do not increases, it gives them stimuli to leave and switch to other organizations where pay will increase with passing year significantly.

All the suggested strategies are summed up here with the frequency of responses.

\section{Table 1}

Proposed retention strategies

\begin{tabular}{lc}
\hline \multicolumn{1}{c}{ Proposed retention strategies } & Percentage \\
\hline Aligning background with job duties & 14 \\
Valuing experience & 12 \\
Continuous follow-up & 11 \\
A mind reader Boss & 10 \\
Giving equal value to all & 9 \\
Breaking stereotypes & 8 \\
Understanding distinctive work pattern & 7 \\
Practicing job rotation & 7 \\
Removing fear of job insecurity & 6 \\
Eliminating undue influence & 6 \\
Personal discretion on job & 5 \\
Increasing increment & 5 \\
\hline
\end{tabular}




\section{Discussion}

This research brings out some unique results. Some of the strategies that faculties have suggested truly describe the practical scenario of today. The findings have significant implications for the success of achieving organizational goals. Employees spend the most waking hours in the workplace by giving their best effort. With each passing day, the sincere employees start to form a belief that their organizations will also value them, recognize them in future for honest performance. In absence of proper communication, misunderstanding crops up and some other time organizations forget to nurture and pay heed to the feelings of employees. The obtained responses have major practical implications in the education sector. If faculty members are assigned courses in accordance with their skills and preferences then they will feel motivated to work and feel the joy of teaching. Many teachers feel that their institutes should give proper attention to understanding their desire, likings and disliking, if it happens then satisfaction will only rise and retain them. Continuous follow-up also increases the desirability for the organization. It has a strong indirect effect on all employees. Teachers like to stay with the institutes where their experience is evaluated properly by giving it value. So thus the major findings have a strong role to play in retaining teachers for a long term.

Faculties or teachers around the universities that suggested breaking stereotypes, understanding distinctive work pattern or practicing job rotation signify that the job of teaching at times gets monotonous and that's why they were not having any more satisfaction from their job life which creates the intention to leave or do something else. This group of teachers who wanted something different means they want their universities to understand their need to be involved in other tasks. After working for a long time, there is a feeling of attachment but this attachment cannot give them mental satisfaction for which they do would like to search an alternative job place. So their viewpoint is university deans or chairpersons should understand their latent talent and deploy them in other activities so that the monotony vanishes and they decide to stay within.

Personal discretion and increasing increment with time are two strategies or suggestions by some faculties. These points mean that some kind of liberty or freedom over the job is highly missing in their workplace that is putting them off and they would like to see a condition where their jobs will be given that required freedom or jurisdiction. A happy employee would never want to leave the workplace. For some other faculties, it is also a consideration that financial remuneration increases. From this survey, it is observed that a few faculties do have the high need of money. Money is not the primary reason to be retained for all respondents but for one group of faculties, it matters a lot. If annual increment fails to live up to the extended cost incurred then they feel like to look for another job. So they claim a significant amount of increment each year which will boost their desire to stay at their workplace for long.

For non-educational organizations, these findings work as well. Significant studies have shown that employees decide to stay based on the satisfaction that derives from the job. The suggestion which has got the maximum response in this research, which is aligning background with job duties, is one of the basic factors that employees consider for staying or leaving an organization. Research suggests that person-organization fit may provide significant insights into individuals' adjustments to organizations (Holland, 1985). O'Reilly, Chatman, and Caldwell (1991) proposed that job satisfaction levels will go up if there is a proper fit between the qualities of the applicants and the job. This study was conducted on employees of government agencies and public accounting firms.

Other findings - understanding distinctive work pattern, practicing job rotation, removing the fear of job insecurity are some strategies that some teachers opted for are something unique phenomenon that came along with this research regarding staying or leaving for other business organizations. People from well-paid bank jobs resign out of frustration due to being stuck in one position for years with no scope of performing something different. The corporate politics also makes it difficult to survive in some places. 
Faculty retention: Strategies suggested by faculty members of select private universities in Dhaka city

Claiming equal value or fair judgment also plays a role in the decision to stay or leave companies. Some employees decide to leave organization due to ineffective performance assessment and perception of job unfairness (Weiss \& Cropanzano, 1996). Continuous follow up that many teachers opted for is a sought for variable in other organizations too. A specific relationship exists between managerial communication and employee performance in the banking sector (Shahid, 2017).

\subsection{Significance of the research findings for further study}

These research findings bring out some major strategies of employee retention to be applied in a workplace with a view to developing human resource for longer term making them assets for organizations. By extracting suggestions from employees, various points and layers of feelings have been brought to light. Organizations and policymakers have got now trails to conduct a study based on each finding expressed by employees. Each finding has got the significance and scope to be studied further regarding its impact on their performance. This research extracts some crucial findings regarding employee behavior, expectations and its relation with productivity. Respondents pointed out to be valued for their experience, getting offered jobs and duties that match their skills, a regular follow up and a departmental head who is amicable and considerate with vision. So it is found that non-financial elements are on high demand. This is another striking contribution of this research. Further study can be started from this end.

\subsection{Implication}

This research presents the findings that have ample merits for application. Teachers who have worked for long time and who have respect and high regards for their job, would like to see the suggestions implemented. Practicing such strategies will augment the motivation level and desirability towards work for the respondents. It is not difficult for the universities to apply the strategies, all they need to be more cooperative and humane towards the employees who are working for a long time and continuously add value. Just a change in the mindset is needed. For example, a sincere conversation before imposing new task and a regular follow up are something that can be done with less effort by the departmental head. A little more time will be needed for that for a dean or chairperson to perform this. But if can be done, this practice will raise motivation level to a great extent.

This research also offers significant scope for the learners of human resource management. People who study and aspire to join this field will find different reasons for job dissatisfaction and varied options for employee retention. This knowledge will help them in having a greater idea about employees, unspoken words about how they feel while they work which will add to their expertise in better dealing with human resource. This study also holds massive importance for teachers and wannabe teachers as well. New teachers will get to know about the retention scenario. They will get to see more closely about the retention strategies sought for to sustain in the teaching industry. This knowledge will help them to communicate their feelings to respective offices or to departmental heads.

\subsection{Limitation}

As the survey was conducted in a particular region in the capital, Dhaka of Bangladesh, the results are area based, may not be equally applicable in the other areas. Culture specificity also plays a key role in the suggestions regarding employee retention. With the high rate of unemployment in Bangladesh employees feel the extreme need to be retained.

\subsection{Conclusion}

It is a dream for every organization to work with the assistance of a well maintained and flexible workforce which is no less than assets. But it is also no less than a big challenge to retain workforce like that. Loyal employees are like the asset that can be molded for a bigger competitive advantage. It is the internal people in an organization that make the outside people- customers happy. Working for a long time with enthusiasm is a 
Abdullah, A. M.

difficult thing, employees lose focus. But organizations have to work like a family and pay attention to its employees so that no confusion crops up and employees can be turned into a source of distinctive competency by implementing the suggestion from them.

\section{References}

Abbasi, S. M., \& Hollman, K. W. (2000). Turnover: The real bottom line. Public Personnel management, 29(3), 333-342. https://doi.org/10.1177/009102600002900303

Abdali, F. (2011). Impact of employee turnover on sustainable growth of organization in computer graphics sector of Karachi, Pakistan. Afro Asian Journal of Social Sciences, 2(4), 1-24. https://doi.org/10.2139/ssrn.1907372

Allan P. (2004). Human resource management (2nd ed.). London: Thompson learning.

Arik, P. (2011). The effect of financial and financial compensation to the employee performance. Paper presented in the 2nd International Research Symposium in Service Management.

Choudhary, S. (2016). A study on retention management: how to keep your top talent. International Journal of Advanced Research in Management and Social Sciences, 5(3), 17-31.

Clarke, K. F. (2001). What businesses are doing to attract and retain employee: Becoming an employer of choice. Employee Benefits Journal, 26(1), 34-37.

Dessler, G. (2008). Human resource management (11th ed.). New Delhi: Prentice Hall of India.

Eyster, L., Johnson, R. W., \& Toder, E. (2008). Current strategies to employ and retain older workers. Urban Institute.

Fisher, C. D., Schoenfeldt, L. F., \& Shaw, J. B. (2007). Maintaining human resources (5th ed.). New Delhi: Dream-tech Press.

Fitz-enz, J. (1990). Getting and keeping good employees. Personnel, 67(8), 25-29.

Fitzenz, J. (1997). It's costly to lose good employees. Workforce, 76(8), 50-51.

Garg, P., \& Rastongi, R. (2006). New model of job design motivation employees performance. Journal of Management Development, 25(6), 572-587. https://doi.org/10.1108/02621710610670137

Hackman, J. R., \& Oldham, G. R. (1980). Work redesign. MA: Addison-Wesley.

Harris, J. (2000). Finding and keeping great employees. Training, 36(4), 118-123.

Hewitt, P. (2002). High performance workplaces: The role of employee involvement in a modern economy. Department of Trade and Industry, Report No: SW1H 0ET.

Holland, J. L. (1985). Making vocational choices (2nd ed.). Englewood Cliffs, NJ: Prentice-Hall.

Hytter, A. (2007). Retention strategies in France and Sweden. The Irish Journal of Management, 28(1), 59-79.

Jadhav, S., Jadhav, S. \& Lavanya, M. (2014). Strategies for employee retention in Indian higher education. International Journal of Education and Psychological Research, 3(4), 22-26.

Kyndt, E., Dochy, F., Michielsen, M., \& Moeyaert, B. (2009). Employee retention: Organizational and personal perspectives. Vocations and Learning, 2(3), 195-215. https://doi.org/10.1007/s12186-009-9024-7

Lincoln, J. R., \& Kalleberg, A. L (1996). Commitment, quits, and work organization in Japanese and US plants. Industrial and Labor Relations Review, 50(1), 39-59. https://doi.org/10.1177/001979399605000103

Miller, N., Erickson, A., \& Yust, B. (2001). Sense of place in the workplace: The relationship between personal objects and job satisfaction and motivation. Journal of Interior Design, 27(1), 35-44.

https://doi.org/10.1111/j.1939-1668.2001.tb00364.x

Nazia, S., \& Begum, B. (2013). Employee retention practices in Indian corporate: A study of select MNCs. International Journal of engineering and management sciences, 4(3), 361-368.

Noah, Y. (2008). A study of worker participation in management decision making within selected establishments in Lagos, Nigeria. Journal of Social Science, 17(1), 31-39.

Oginni, B. O., Ogunlusi, C. F., \& Faseyiku, I. O. (2013). A study of employee retention strategies and organizational survival in private universities in South West, Nigeria. The International Journal of Management, 2(1), 1-17.

O'Reilly III, C. A., Chatman, J., \& Caldwell, D. F. (1991). People and organizational culture: A profile 
Faculty retention: Strategies suggested by faculty members of select private universities in Dhaka city comparison approach to assessing person-organization fit. Academy of management Journal, 34(3), 487-516.

Osteraker, M. C. (1999). Measuring motivation in a learning organization. Journal of Work Place Learning, 11(2), 73-77. https://doi.org/10.1108/13665629910260798

Parker, O., \& Wright, L. (2001). Pay and employee commitment: The missing link. Ivey Business Journal, 65(3), 70-79.

Peggy, N., \& Bernard, O. (2016). Analysis of employee retention strategies on organizational performance of hospitals in Mombasa County. International Journal of Business and Management Invention, 5(6), 40-45.

Shahid, A. (2017). Strategies used by banking managers to reduce employee turnover. Retrieved from https://scholarworks.waldenu.edu/dissertations/3633/

Stein, N. (2000). Winning the war to keep top talent: Yes you can make your workplace invincible. Fortune, 141(11), 132-138.

Walker, J. W. (2001). Perspectives. Human Resource Planning, 24(1), 6-10.

Weiss, H. M., \& Cropanzano, R. (1996). Affective events theory: A theoretical discussion of the structure, causes and consequences of affective experiences at work. In B. M. Staw \& L. L. Cummings (Eds.), Research in organizational behavior: An annual series of analytical essays and critical reviews (Vol. 18, pp. 1-74). USA: Elsevier.

Wells, M., \& Thelen, L. (2002). What does your workspace say about you? The influence of personality, status, and workspace on personalization. Environment and Behavior, 34(3), 300-321.

https://doi.org/10.1177/0013916502034003002 
Abdullah, A. M. 